\title{
Squamous Cell Carcinoma of the Anal Transitional Zone after Ileal Pouch Surgery for Ulcerative Colitis: Systematic Review and Treatment Perspectives
}

\author{
Gianluca Pellino ${ }^{a, b} \quad$ Christos Kontovounisios $^{a, b} \quad$ Diana Tait $^{c}$ \\ John Nicholls ${ }^{a}$ Paris P. Tekkis ${ }^{a, b}$ \\ a Division of Surgery and Cancer, Imperial College London, London, UK; ${ }^{b}$ Department of \\ Colorectal Surgery, The Royal Marsden Hospital, London, UK; ${ }^{c}$ Radiotherapy Department, \\ The Royal Marsden Hospital, London, UK
}

\section{Keywords}

Squamous cell carcinoma $\cdot$ Pouch $\cdot$ Ulcerative colitis

\begin{abstract}
Background: Few cases of pouch-related cancers have been reported in ulcerative colitis (UC), and squamous cell carcinoma (SCC) is very rare. Method: A systematic review of the literature was performed to identify all unequivocal cases of pouch-related SCC in UC patients. Results: Eight cases of SCC developing after ileal pouch-anal anastomosis (IPAA) have been observed since 1978. Two arose from the pouch mucosa and 6 from below. The pooled cumulative incidence of SCC is below $0.06 \%$ after IPAA. Many patients had neoplasia on the preoperative specimen, but squamous metaplasia of the pouch or anorectal mucosa may have an important role in SCC. These patients are rarely offered chemoradiation therapy and the outcome is poor. Selected patients with SCC located close to the pouch outlet can be
\end{abstract}




\section{Case Reports in Oncology}

treated with chemoradiation prior to consideration of surgery and salvage their pouch. A chemoradiation regimen is suggested to avoid pouch excision in these patients. Conclusions: SCC is rare after pouch surgery but associated with extremely poor survival. Very low SCC can be managed with chemoradiation treatment, preserving the pouch and avoiding surgery, even in older patients. The role of pouch metaplasia, surveillance frequency, and treatment modalities after IPAA need further studying.

(C) 2017 The Author(s)

Published by S. Karger AG, Basel

\section{Introduction}

Squamous cell carcinoma (SCC) after ileal pouch-anal anastomosis (IPAA) for ulcerative colitis (UC) is very rare $[1,2]$. SCC is extremely sensitive to chemoradiation therapy (CRT), but an ileal pouch is generally considered a contraindication to radiotherapy. No validated guidelines exist on how to treat SCC after IPAA.

Few cases of SCC in IPAA patients have been described in the literature, with variable treatments and unpredictable outcomes. We report the successful management of an SCC of the anal transitional zone (ATZ) after IPAA and systematically review the literature for IPAArelated SCC.

\section{Materials and Methods}

\section{Short Report}

An 84-year-old man was diagnosed with UC in 1998. He was steroid-refractory and had no family history of colorectal cancer. He underwent IPAA with hand-sewn ileoanal anastomosis and loop ileostomy in 2001. Histology showed no dysplasia or malignancy. Stoma reversal was performed 3 months later. The patient has had good functional outcomes but suffered from several episodes of pouchitis. In 2014, he was seen at the outpatient clinic due to a nodule in the anal canal which had rapidly increased in size (Fig. 1). The patient underwent flexible pouchoscopy and examination under general anaesthesia with biopsies, pelvis MRI (Fig. 2a-d) and chest-abdomen-pelvis CT scan. Findings were consistent with a moderately well-differentiated SCC of the ATZ, with no evidence of distant disease (T1N0M0).

\section{Systematic Review}

We performed a systematic review of the literature to identify SCC arising from the pouch or from the ATZ of UC patients. Inclusion criteria were unequivocal diagnosis of SCC that can be reasonably considered as de novo carcinoma, diagnosis of UC, and availability of adequate information. Studies including patients with conditions other than UC were only included if UC patients were identifiable.

\section{Data Search}

Available data of all patients operated on with IPAA between 1978 and 2016 were evaluated. The literature searches were carried out on PubMed and EMBASE. Keywords and medical subject headings (MeSH) used were: "restorative proctocolectomy," "ulcerative coli- 


\section{Case Reports in Oncology}

Case Rep Oncol 2017;10:112-122

DOI: $10.1159 / 000455898$

(c)

2017 The Author(s). Published by S. Karger AG, Base www.karger.com/cro

Pellino et al.: Squamous Cell Carcinoma of the Anal Transitional Zone after Ileal Pouch

Surgery for Ulcerative Colitis: Systematic Review and Treatment Perspectives

tis," "squamous cell carcinoma," "pouch," "IPAA," and "SCC." Cross-referencing and related articles suggested by database browsers were reviewed. Data were pooled and analysed.

\section{Results}

The multidisciplinary meeting recommendation for the present case was to proceed with the conventional radiation dose to the expected effects on the ileal pelvic pouch and to the nodal spread. The patient received 54 Gy in 30\# radiotherapy with concomitant capecitabine (Fig. 2e). He received a single administration of mitomycin (13.5 $\mathrm{mg}$ ) and daily capecitabine tablets during the course of radiotherapy $(1,300 \mathrm{mg} /$ day $)$. Treatment was completed in January 2015. He had a complete response (Fig. 3, Fig. 4) and only suffered from pain and ulceration to the skin during CRT. At the 24-month follow-up, the patient has acceptable function, no incontinence nor urgency, and good control of flatus. Digital examination of the ileoanal anastomosis did not show any stricture. On endoscopy, the mucosa of the pouch was healthy, but a stricture with inflammation was noticed at the pouch inlet (Fig. 5), compatible with active, acute pouchitis. Endoscopic balloon dilatation was uneventfully carried out.

The flow chart of the systematic study selection is shown in Figure 6. A literature review found 454 papers. After removing papers which did not fit inclusion criteria, only 5 papers reporting on 7 SCC were available for analysis (Table 1). When matching the series of several centres, including a total of 5,136 patients, only 3 cases of SCC have been observed over time, corresponding to a cumulative incidence of $0.058 \% 25$ years after IPAA [3-7]. Five SCC developed from either the ATZ or rectal cuff [7-9] and 2 from the mucosa of the pouch [10,11].

Treatment shows variability depending on the time of the report and tumour location. Out of 2 patients with SCC of the pouch, 1 with SCC close to the ileal pouch inlet was unsuitable for CRT and died 6 months after pouch excision [10] and 1 had pouch excision followed by CRT (mitomycin C, 5-fluorouracil, and local radiotherapy) with no response [11]. Only 1 paper reported CRT for ileal pouch-related SCC arising from the rectal cuff [8]. The patient was a 47-year-old woman, who received 5-fluorouracil, mitomycin $\mathrm{C}$, and external beam radiation therapy and appeared to have a clinical response. Long-term follow-up is lacking.

\section{Discussion}

Several cases of IPAA-related cancers have been reported $[1,12,13]$. A systematic review of the literature suggested that the cumulative risk of "de novo" IPAA-related cancer is $0.33 \%$ [1] after removing dubious cases, meaning those that should have been considered either persistence or recurrence of previously treated cancer. Dysplasia or cancer on the colectomy specimen is the strongest predictor of IPAA-related cancer $[1,4,7]$. Patients with these features are 8 times more likely of developing IPAA-related cancer, irrespective of mucosectomy [1].

Seven [7-11] IPAA-related SCC have been described, of which 5 developed from either the ATZ or rectal cuff [7-9] and 2 from the mucosa of the ileal pouch [10,11] (Table 1). Patients' features and treatments delivered are poorly described. Dysplasia on the specimen is considered a risk factor for SCC [4], but metaplasia of the ileal pouch could underlie SCC, 


\section{Case Reports in Oncology}

Case Rep Oncol 2017;10:112-122

DOI: $10.1159 / 000455898$

(C) 2017 The Author(s). Published by S. Karger AG, Basel www.karger.com/cro

Pellino et al:: Squamous Cell Carcinoma of the Anal Transitional Zone after Ileal Pouch

Surgery for Ulcerative Colitis: Systematic Review and Treatment Perspectives

especially squamous metaplasia $[10,11]$. This is poorly addressed in UC, whereas more attention is paid to the detection of dysplasia for subsequent cancer concern and surveillance.

CRT is the treatment of choice for anal SCC, but it can also achieve complete response in up to $66 \%$ of patients with rectal SCC [14]. It is largely agreed that pelvic irradiation is contraindicated in patients with a pelvic ileal pouch because of the predictable risk of radiation enteritis, which is likely to cause pouch failure due to structural damage to the mucosa and body of the reservoir. However, no studies have addressed the actual role of radiotherapy in these patients, and these considerations might be even more interesting under the light of newer treatment regimens. One paper reported CRT [8] for an early tumour discovered on routine anal biopsy, and no description is provided concerning the stage $[8,11]$. Moreover, the patient suffered from poor function, with seepage and 20 bowel movements per day. When acute toxicity settled down, good function was restored, but the patient required diphenoxylate hydrochloride and atropine sulfate 8 times daily. No data are available concerning the long-term effects of CRT and treatment outcomes [8]. The largest series on the topic suggested that patients with rectal cancer can have IPAA [15], but radiotherapy before pouch surgery impairs subsequent function and increases failure rates [16]. European Guidelines currently recommend that radiotherapy should precede pouch surgery and should be avoided after IPAA, even acknowledging that the evidence for that assumption is low [17]. Indeed, a recent survey among colorectal surgeons showed moderate agreement towards that [18].

SCC located in the pouch body seem to be more aggressive and might be difficult to treat with radiation therapy. Out of 2 patients with SCC occurring in the ileal pouch, 1 with SCC close to the ileal pouch inlet was unsuitable for CRT and died 6 months after pouch excision [10],and 1 was approached with pouch excision followed by CRT (mitomycin C, 5-fluorouracil, and local radiotherapy) but had no response [11].

We were able to manage an SCC of the ileal pouch by means of a CRT protocol that achieved complete response, without the adverse effects of radiotherapy on pouch function. Avoiding excessive worsening of function is important, especially in frail patients, who may suffer from serious dehydration and electrolyte loss secondary to increased ileal pouch-anal output. The early outcome was acceptable, and no particular measures were required apart from loperamide administration. In the long term, the patient did not need any surgical treatment, which is associated with a doubled risk of failure and dysfunction over time in IPAA $[19,20]$. This is a safer alternative for patients otherwise fated to undergo ileal pouch excision. However, the decision on how to treat patients with SCC and anal cancer of the pelvic pouch needs to be individualized, and patients and their relatives should participate in the decision-making process. They should be warned that further treatments may be needed and accept the risks.

Our report also offers another perspective to be considered. Scheduled follow-up of the pouch is usually not recommended in UC patients without risk factors for cancer [17]. Indeed, the risk of colorectal cancer arising from the rectal remnant or ATZ is lower after IPAA than the lifetime risk of cancer in the general population [1]. However, endoscopic follow-up and surveillance after IPAA probably need to be further elucidated $[13,21]$ because SCC may occur at some point even in patients with no known risk factor [1]. 


\section{Case Reports in Oncology}

\section{Conclusion}

Early detection is the key to preserve the pouch in patients who develop IPAA-related SCC. CRT according to our regimen could be considered in SCC arising from the rectal cuff or ATZ. This could be the first-line approach in anal SCC after IPAA, but it could also be advocated for other types of cancer, hopefully increasing the success rates and survival. Metaplasia of the pouch might play a role in SCC, but this remains to be further elucidated. Patients with pelvic pouches receiving CRT should be followed up with scheduled long-term appointments including pouchoscopy to diagnose recurrence and late adverse effects of radiation.

\section{Acknowledgements}

The authors wish to thank the Biomedical Research Centre (BRC) at The Royal Marsden NHS Foundation Trust and The Institute of Cancer Research, London.

\section{Statement of Ethics}

Written informed consent for patient information and images to be published was provided by the patient. This study was conducted following the guidelines for Good Clinical Practice.

\section{Disclosure Statement}

The authors have no conflict of interest to disclose related to this paper.

\section{Author Contributions}

G.P. and C.K. collected literature data, drafted the review, and approved publication of the manuscript. D.T., J.N., and P.P.T. reviewed the manuscript and approved publication of the manuscript.

\section{References}

1 Selvaggi F, Pellino G, Canonico S, Sciaudone G: Systematic review of cuff and pouch cancer in patients with ileal pelvic pouch for ulcerative colitis. Inflamm Bowel Dis 2014;20:1296-1308.

2 Das P, Johnson MW, Tekkis PP, Nicholls RJ: Risk of dysplasia and adenocarcinoma following restorative proctocolectomy for ulcerative colitis. Colorectal Dis 2007;9:15-27.

-3 Fazio VW, Kiran RP, Remzi FH, et al: Ileal pouch anal anastomosis: analysis of outcome and quality of life in 3,707 patients. Ann Surg 2013;257:679-685. 
4 Derikx LA, Kievit W, Drenth JP, et al: Prior colorectal neoplasia is associated with increased risk of ileoanal pouch neoplasia in patients with inflammatory bowel disease. Gastroenterology 2014;146:119-128.e1.

5 Al-Sukhni W, McLeod RS, MacRae H, et al: Oncologic outcome in patients with ulcerative colitis associated with dyplasia or cancer who underwent stapled or handsewn ileal pouch-anal anastomosis. Dis Colon Rectum 2010;53:1495-1500.

-6 Andersson P, Norblad R, Söderholm JD, Myrelid P: Ileorectal anastomosis in comparison with ileal pouch anal anastomosis in reconstructive surgery for ulcerative colitis - a single institution experience. J Crohns Colitis 2014;8:582-589.

7 Kariv R, Remzi FH, Lian L, et al: Preoperative colorectal neoplasia increases risk for pouch neoplasia in patients with restorative proctocolectomy. Gastroenterology 2010;139:806-812, 12.e1-2. Schaffzin DM, Smith LE: Squamous-cell carcinoma developing after an ileoanal pouch procedure: report of a case. Dis Colon Rectum 2005;48:1086-1089. Ravitch MM: The reception of new operations. Ann Surg 1984;200:231-246.

D'Souza FR, Lim M, Hainsworth A, et al: A case of squamous cell carcinoma in an ileoanal pouch. Colorectal Dis 2011;13:e314-e315.

11 Macdonald E, Gee C, Kerr K, et al: Squamous cell carcinoma of an ileo-anal pouch. Colorectal Dis 2010;12:945-946.

12 Egan L, D'Inca R, Jess T, et al: Non-colorectal intestinal tract carcinomas in inflammatory bowel disease: results of the 3rd ECCO Pathogenesis Scientific Workshop (II). J Crohns Colitis 2014;8:19-30.

13 Annese V, Beaugerie L, Egan L, et al: European evidence-based consensus: inflammatory bowel disease and malignancies. J Crohns Colitis 2015;9:945-965.

14 Rasheed S, Yap T, Zia A, McDonald PJ, Glynne-Jones R: Chemo-radiotherapy: an alternative to surgery for squamous cell carcinoma of the rectum - report of six patients and literature review. Colorectal Dis 2009;11:191-197.

15 Remzi FH, Preen M: Rectal cancer and ulcerative colitis: does it change the therapeutic approach? Colorectal Dis 2003;5:483-485.

16 Wu XR, Kiran RP, Remzi FH, et al: Preoperative pelvic radiation increases the risk for ileal pouch failure in patients with colitis-associated colorectal cancer. J Crohns Colitis 2013;7:e419-e426.

-17 Øresland T, Bemelman WA, Sampietro GM, et al: European evidence based consensus on surgery for ulcerative colitis. J Crohns Colitis 2015;9:4-25.

18 Selvaggi F, Pellino G, Ghezzi G, et al: A think tank of the Italian Society of Colorectal Surgery (SICCR) on the surgical treatment of inflammatory bowel disease using the Delphi method: ulcerative colitis. Tech Coloproctol 2015;19:627-638.

19 Tekkis PP, Lovegrove RE, Tilney HS, et al: Long-term failure and function after restorative proctocolectomy - a multi-centre study of patients from the UK National Ileal Pouch Registry. Colorectal Dis 2010;12:433-441.

20 Pellino G, Selvaggi F: Outcomes of salvage surgery for ileal pouch complications and dysfunctions. The experience of a referral centre and review of literature. J Crohns Colitis 2015;9:548-557.

-21 Derikx LA, Nissen LH, Oldenburg B, Hoentjen F: Controversies in pouch surveillance for patients with inflammatory bowel disease. J Crohns Colitis 2016;10:747-751. 


\section{Case Reports in Oncology}

Pellino et al.: Squamous Cell Carcinoma of the Anal Transitional Zone after Ileal Pouch

Surgery for Ulcerative Colitis: Systematic Review and Treatment Perspectives

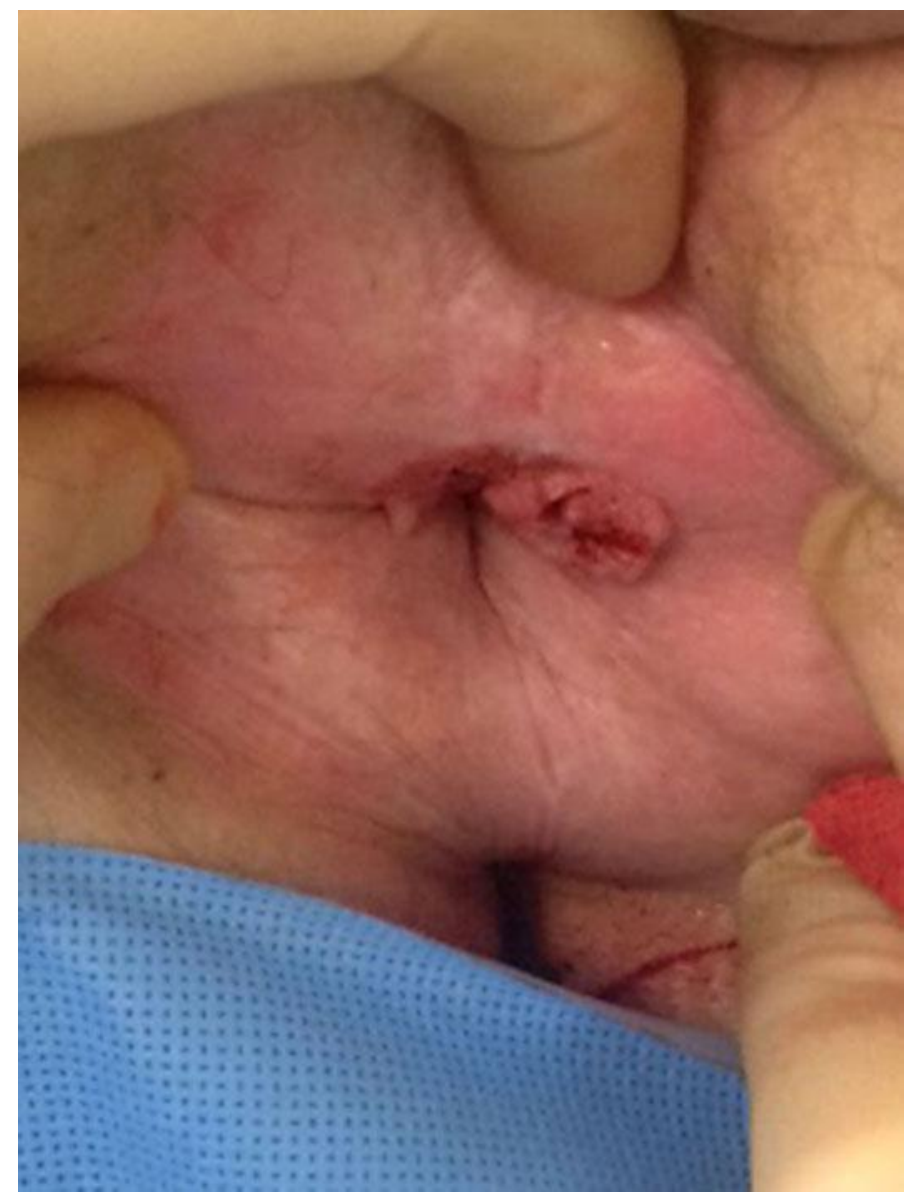

Fig. 1. Squamous cell carcinoma arising from the anal transitional zone at 1-3 o'clock and extending to the anal skin in a patient with an ileal pelvic pouch for ulcerative colitis. The lump had been growing rapidly over a short time. 


\section{Case Reports in Oncology}
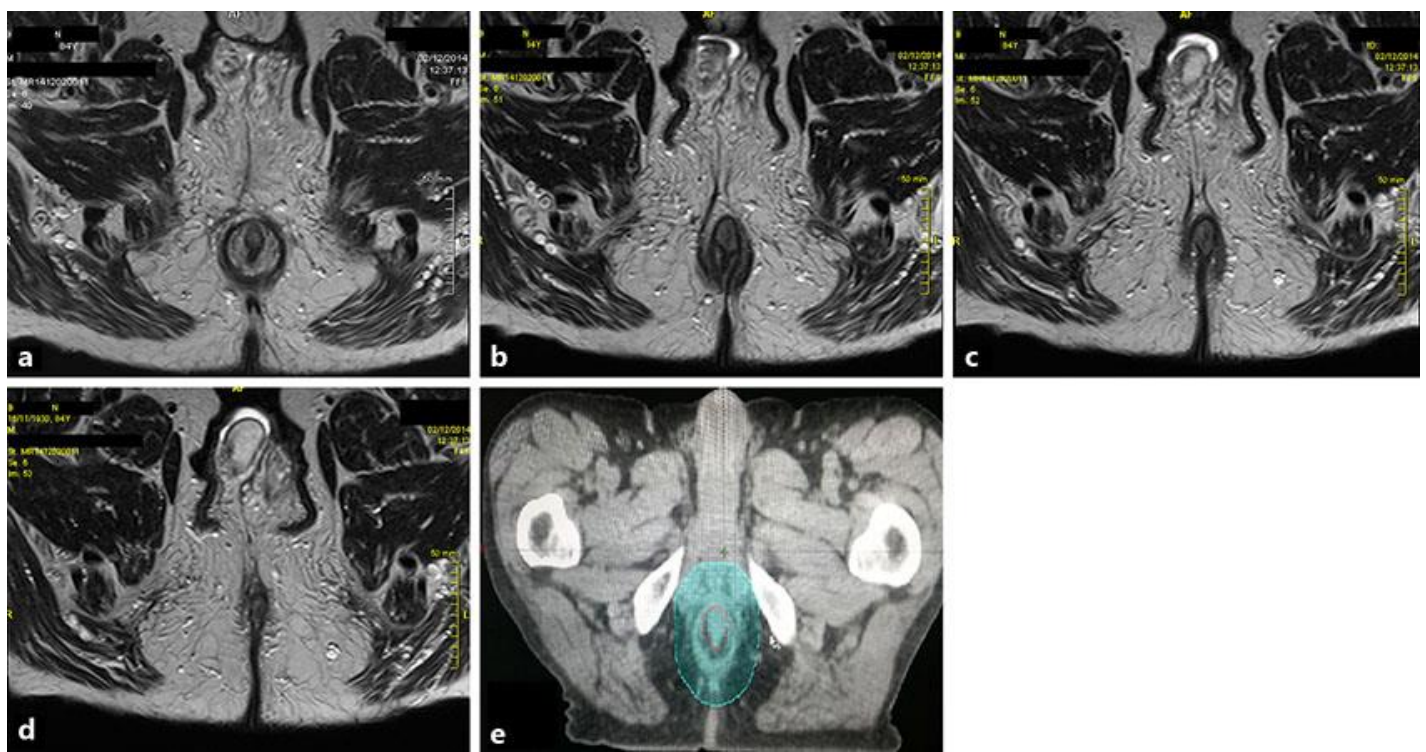

Fig. 2. a-d Magnetic resonance scan. a The lesion can be noticed arising in proximity of the ileoanal anastomosis, where the 2 different layers meet, reaching the external skin of the anal canal. e The inner circle runs around the squamous cell carcinoma, the outer is used to plan chemoradiation therapy, involving the lower portion of the pouch body and the ileoanal anastomosis.

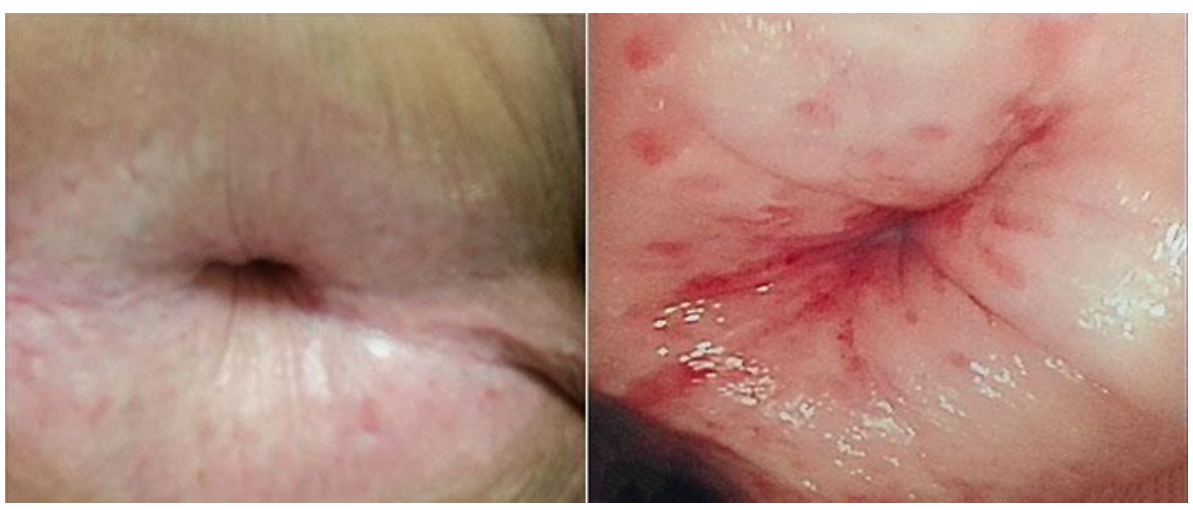

Fig. 3. Appearance of the site of the cancer after chemoradiation. The patient had a complete response. The skin showed no signs of disease, and no stricture of the ileoanal anastomosis was observed (left). Magnified view by means of flexible endoscope showed no abnormalities of the perianal skin and anal canal (right). 


\section{Case Reports in Oncology}

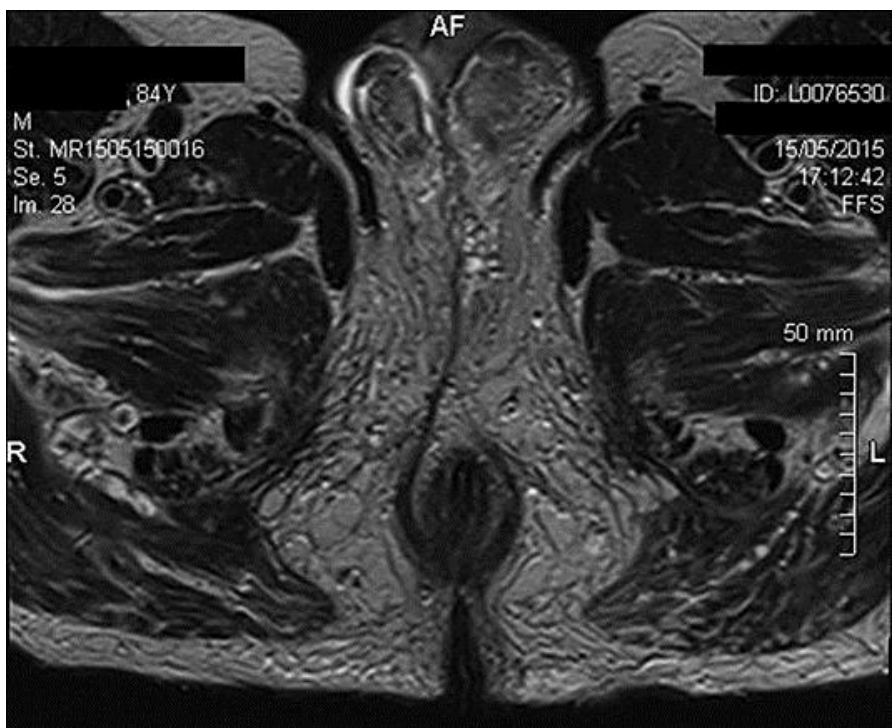

Fig. 4. Magnetic resonance appearance of the cancer after chemoradiation. The cancer has completely regressed.

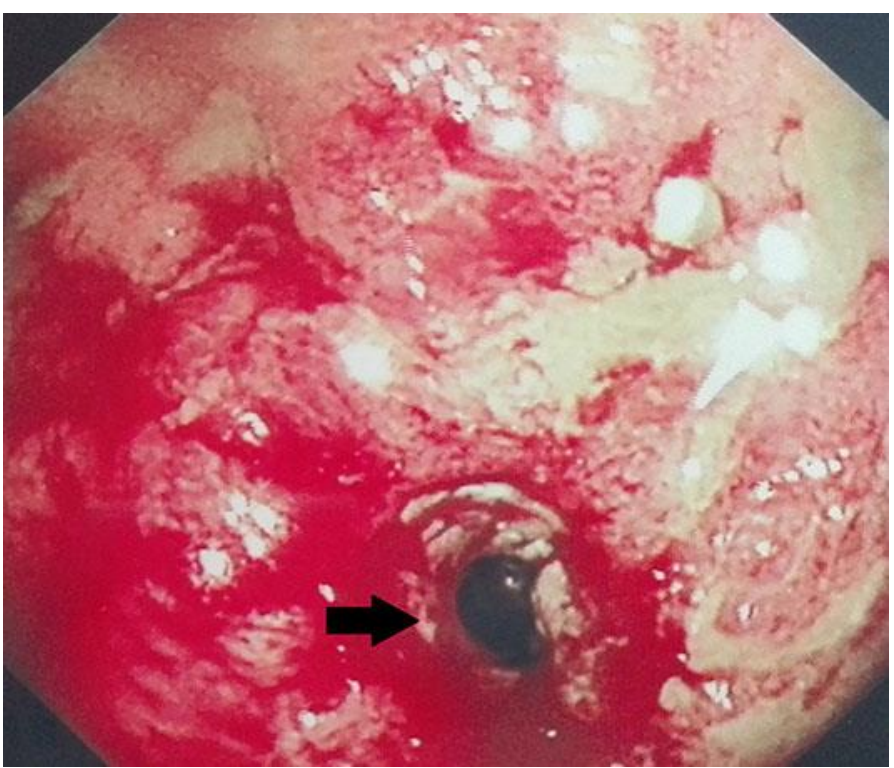

Fig. 5. A stricture of the pouch inlet (arrow) with marked mucosal inflammation was found on endoscopy. 
\begin{tabular}{l|l} 
DOI: $10.1159 / 000455898$ & (C) 2017 The Author(s). Published by S. Karger AG, Basel \\
\hline
\end{tabular} www.karger.com/cro

Pellino et al.: Squamous Cell Carcinoma of the Anal Transitional Zone after Ileal Pouch

Surgery for Ulcerative Colitis: Systematic Review and Treatment Perspectives

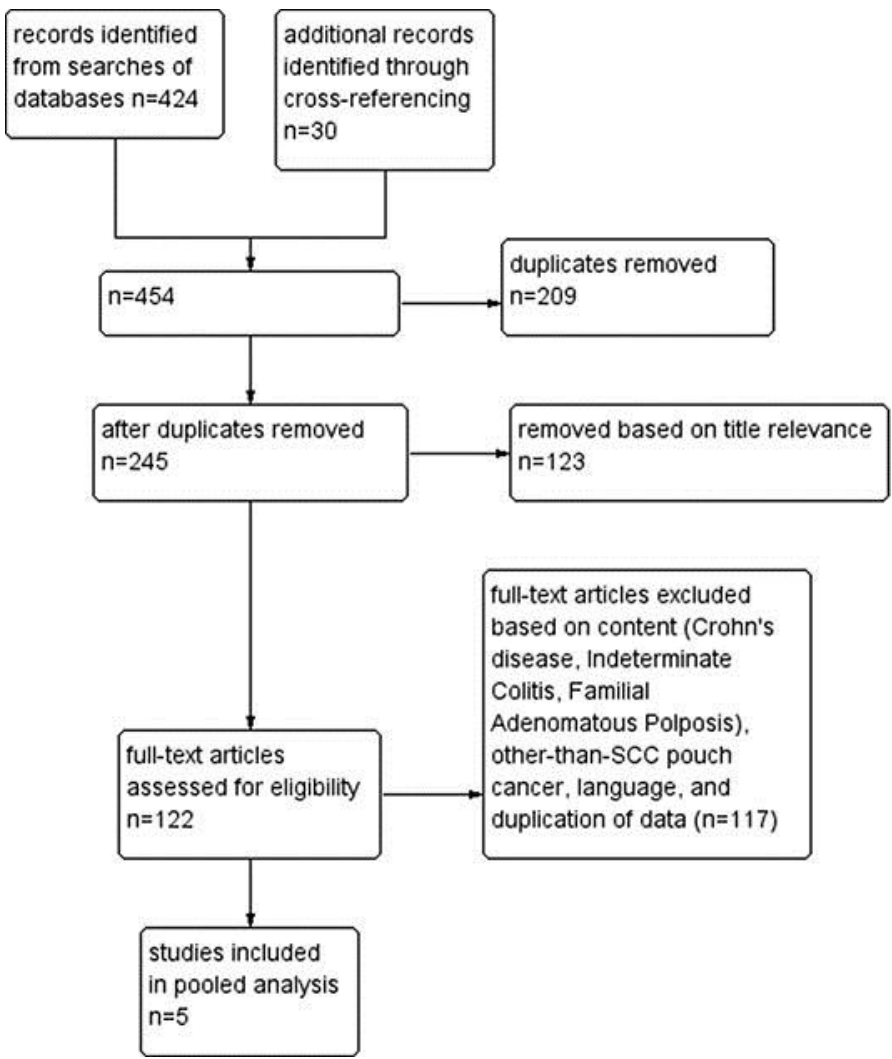

Fig. 6. Flow chart for the systematic review of the literature. 


\section{Case Reports in Oncology}

Pellino et al.: Squamous Cell Carcinoma of the Anal Transitional Zone after Ileal Pouch

Surgery for Ulcerative Colitis: Systematic Review and Treatment Perspectives

Table 1. Published cases of pouch-related squamous cell carcinomas

\begin{tabular}{|c|c|c|c|c|c|c|c|}
\hline First author [Ref.] & Year & $\begin{array}{l}\text { Years } \\
\text { before } \\
\text { IPAA }\end{array}$ & $\begin{array}{l}\text { Risk } \\
\text { factor }\end{array}$ & Pouchitis & $\begin{array}{l}\text { Tumour } \\
\text { site }\end{array}$ & Treatment & $\begin{array}{l}\text { Long-term } \\
\text { follow-up }\end{array}$ \\
\hline Ravitch [9] & 1984 & 7 & NS & NS & rectal cuff & NS & NS \\
\hline Schaffzin [8] & 2005 & 42 & NS & yes & rectal cuff & CRT & NS \\
\hline D’Souza [10] & 2010 & NS & $\mathrm{CC}$ & yes & pouch & pouch excision & alive (6 m) \\
\hline Macdonald [11] & 2010 & NS & NS & no & pouch & surgery $\rightarrow$ CRT & $\operatorname{died}(12 \mathrm{~m})$ \\
\hline \multirow[t]{3}{*}{ Kariv [7] } & 2010 & NS & NS & NS & ATZ & NS & NS \\
\hline & & NS & NS & NS & ATZ & NS & NS \\
\hline & & NS & NS & NS & ATZ & NS & NS \\
\hline Present case & 2016 & 3 & no & yes & ATZ & CRT & $\begin{array}{l}\text { alive with pouch } \\
(24 \mathrm{~m})\end{array}$ \\
\hline
\end{tabular}

CRT, chemoradiation therapy; ATZ, anal transitional zone; NS, not stated; m, month; CC, colon cancer on specimen. 